\section{Renal growth slope in children with congenital and acquired solitary functioning kidneys}

\author{
Seung Myeon Choi ${ }^{1}$, Hyun Joo Shin ${ }^{1}$, Haesung Yoon ${ }^{1}$, Myeongjee Lee ${ }^{2}$, Yong Seung Lee ${ }^{3}$, \\ Sang Won $\mathrm{Han}^{3}$, Mi-Jung Lee ${ }^{1}$ \\ 'Department of Radiology and Research Institute of Radiological Science, Severance \\ Children's Hospital, Yonsei University College of Medicine, Seoul; ${ }^{2}$ Biostatistics Collaboration \\ Unit, Department of Biomedical Systems Informatics, Yonsei University College of Medicine, \\ Seoul; ${ }^{3}$ Department of Urology and Urological Science Institute, Severance Children's \\ Hospital, Yonsei University College of Medicine, Seoul, Korea
}

Purpose: This study aimed to analyze the renal growth slope in children with congenital and acquired solitary functioning kidneys.

Methods: This retrospective study included all renal ultrasonography examinations performed in children in the agenesis, multicystic dysplastic kidney (MCDK), or nephrectomy group between September 2002 and February 2019. We reviewed the images and recorded the contralateral kidney size only when there was no focal lesion. Linear mixed model or piecewise linear mixed model analyses with a time point of 24 months of age were performed.

Results: There were 132 patients, including 26 patients in the agenesis group, 35 in the MCDK group, and 71 in the nephrectomy group. The nephrectomy group showed the largest baseline kidney size $(7.4 \mathrm{~cm}$ vs. $5.3 \mathrm{~cm}$ in the agenesis group $[P<0.001]$ and $5.2 \mathrm{~cm}$ in the MCDK group $[P<0.001])$ and the smallest overall growth slope $(0.04 \mathrm{~cm} / \mathrm{mo}$ vs. $0.06 \mathrm{~cm} / \mathrm{mo}$ in the agenesis group $[P=0.004]$ and $0.07 \mathrm{~cm} / \mathrm{mo}$ in the MCDK group $[P<0.001])$. However, considering the time point of 24 months for reaching adult renal function, there were significant changes in slope, from $0.1 \mathrm{~cm} / \mathrm{mo}$ before 24 months of age to $0.03 \mathrm{~cm} / \mathrm{mo}$ after 24 months of age in all three groups $(P<0.001)$, without a significant difference among the groups.

Conclusion: Significant changes were found in the renal growth slope before and after 24 months of age, with no significant difference between congenital and acquired solitary functioning kidneys.

Keywords: Solitary kidney; Unilateral renal agenesis; Multicystic dysplastic kidney; Nephrectomy; Ultrasonography

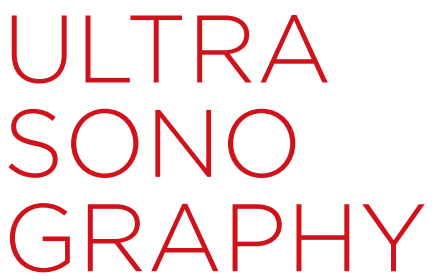

ORIGINAL ARTICLE

https://doi.org/10.14366/usg.20028 pISSN: 2288-5919 • eISSN: 2288-5943 Ultrasonography 2021;40:357-365

Received: February 26, 2020

Revised: September 11, 2020

Accepted: September 12, 2020

Correspondence to:

Mi-Jung Lee, MD, PhD, Department of Radiology and Research Institute of Radiological Science, Severance Children's Hospital, Yonsei University College of Medicine, 50-1 Yonsei-ro, Seodaemun-gu, Seoul 03722, Korea

Tel. $+82-2-2228-7400$

Fax. +82-2-2227-8337

E-mail: mjl1213@yuhs.ac

This is an Open Access article distributed under the terms of the Creative Commons Attribution NonCommercial License (http://creativecommons.org/ licenses/by-nc/4.0/) which permits unrestricted noncommercial use, distribution, and reproduction in any medium, provided the original work is properly cited.

Copyright @ 2021 Korean Society of Ultrasound in Medicine (KSUM)

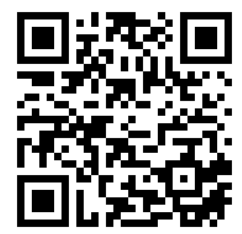

How to cite this article:

Choi SM, Shin HJ, Yoon H, Lee M, Lee YS, Han SW, et al. Renal growth slope in children with congenital and acquired solitary functioning kidneys. Ultrasonography. 2021 Jul;40(3):357365. 


\section{Introduction}

The kidneys are composed of three structures: the pronephros, the mesonephric duct, and the metanephric duct. A normal kidney contains approximately 1 million nephrons, even though the number varies widely, and no new nephrons are formed in human kidneys after approximately 36 weeks of gestation [1]. In normal renal growth after birth, renal length and volume are affected by the overall body size of an individual, including age, height, weight, and body surface area [2]. The glomerular filtration rate (GFR) is considered the best overall indicator of renal function. In children, the GFR increases with age and is calculated with specific equations that are different from those used for adults. Adjusted for body surface area, the GFR reaches the adult level of $\sim 120 \mathrm{~mL} / \mathrm{min} / 1.73$ $\mathrm{m}^{2}$ by approximately 2 years of age [3].

Some pediatric patients may have to live with a solitary functioning kidney due to congenital or acquired conditions. The congenital type includes unilateral renal agenesis and multicystic dysplastic kidney (MCDK), and the acquired type includes nephrectomy for various reasons, such as congenital anomalies, renal trauma, and renal malignancy $[4,5]$.

Unilateral congenital renal agenesis is defined as a unilateral congenital absence of renal tissue due to the failure of embryonic kidney formation. This disease is associated with urological anomalies such as ureteropelvic junction obstruction or vesicoureteral reflux in the contralateral kidneys, hypertension, proteinuria, or impaired renal function, which can require dialysis in up to $50 \%$ of cases [6-8]. MCDK is the most common cystic renal disease in children. Patients with unilateral MCDK may also have anomalies such as vesicoureteral reflux, ureteropelvic junction obstruction, or vesicoureteral junction obstruction, which occur in one-third of patients [9]. Therefore, identifying concomitant contralateral renal abnormalities is important for determining the prognosis of children with unilateral renal agenesis or MCDK. An adequate length of the congenital solitary functioning kidney is a key parameter for renal function [10]. However, according to several theories and some evidence of remaining functional renal tissue in MCDK [11], the renal growth slope may be different between renal agenesis and MCDK [12].

Nephroblastoma is the most common pediatric renal tumor, accounting for at least $90 \%$ of cases [13]. Treatment of unilateral nephroblastoma differs depending on the inclusion of neoadjuvant chemotherapy, but complete resection is the main treatment approach [14]. Removal of one kidney leads to structural and functional changes in the remaining kidney, with creatinine elevation or microalbuminuria [15]. Therefore, after nephrectomy, surveillance of the contralateral kidney including renal growth is important, especially in children.

Previous studies have shown that the contralateral kidney in each of these three disease groups shows compensatory hypertrophy during follow-up [16]. However, most studies have suggested only compensatory renal hypertrophy, and only a few have suggested patterns of size change during follow-up [17-19]. In addition, no studies have assessed differences in growth slope between these three disease groups with different etiologies. Therefore, in this study, we analyzed the growth slope of congenital and acquired solitary functioning kidneys in children belonging to each disease group and assessed the differences between the groups.

\section{Materials and Methods}

\section{Study Design}

This retrospective study was approved by the Institutional Review Board of our institution (4-2019-0585), and the requirement for informed consent was waived. All renal ultrasonography examinations performed between September 2002 and February 2019 in children (under 18 years of age at the time of examination) with congenital or acquired solitary functioning kidneys at our institution were included. The patients with a congenital solitary functioning kidney had unilateral renal agenesis or MCDK, and those with an acquired solitary functioning kidney had undergone unilateral nephrectomy for a primary renal tumor. We excluded examinations that showed abnormal parenchymal echogenicity or focal lesions, including renal cysts, scarring, or hydronephrosis in the contralateral kidney.

Patients' data and images were retrospectively obtained from their electronic medical records and the picture archiving and communication system. Sex, age at the time of each ultrasonography examination, and laboratory results on renal function, including serum creatinine, cystatin C, and estimated GFR within a 2-week interval of each ultrasonography examination, were recorded. The normal range of serum creatinine is $0.3-0.7 \mathrm{mg} / \mathrm{dL}$ for children under age 3 and $0.5-1.0 \mathrm{mg} / \mathrm{dL}$ for children aged 3-18 years. The normal range of cystatin $C$ is $0.59-1.97 \mathrm{mg} / \mathrm{L}$ for infants and $0.50-$ $1.27 \mathrm{mg} / \mathrm{L}$ for children aged $1-18$ years, and that of estimated GFR increases with age up to 2 years and is $90-160 \mathrm{~mL} / \mathrm{min} / 1.73$ $\mathrm{m}^{2}$ for children aged 2-12 years and $110-170 \mathrm{~mL} / \mathrm{min} / 1.73 \mathrm{~m}^{2}$ for children aged 13-18 years. These biomarkers have different normal ranges depending on children's age [20], and the results of multiple follow-up tests in each patient were different. Therefore, we could not classify them as normal or abnormal. The presence of proteinuria was also assessed, if available within 2 weeks of the ultrasonography examinations during follow-up. 


\section{Renal Ultrasonography and Image Review}

Renal ultrasonography examinations were performed by pediatric radiologists using convex or linear transducers of HDI 5000 or IU-22 scanners (Philips Medical Systems, Bothell, WA, USA). The patients were in a supine position during the examinations. Although the measurements of kidney size taken in a supine position can be 2 to $3 \mathrm{~mm}$ larger than those taken in a prone position [21], all patients were measured in the same position in order to enable direct comparisons. One radiologist, blinded to the disease group of the children, reviewed the images and remeasured the kidney size as the maximum bipolar dimension in a longitudinal plane that displayed the best central sinus echoes. Any abnormalities in the renal parenchyma were recorded, and kidneys with focal lesions were excluded from this study.

\section{Statistical Analyses}

The patients were classified into three groups based on disease: agenesis, MCDK, and nephrectomy. Age at the time of each examination, laboratory findings, number of ultrasonography examinations, and size of the contralateral kidney were compared among the three groups. Baseline characteristics of the study populations in the three groups were compared using analysis of variance for continuous variables and the chi-square test for categorical variables. Multiple comparison tests were performed for variables with significant differences among the three groups.

The size of the contralateral kidney without gross lesions was measured several times during the follow-up period, and longitudinal data analysis was implemented as follows. First, the size of contralateral kidney profiles in each patient over time was represented graphically using a spaghetti plot. Second, we investigated the associations between growth of the kidney and diseases using linear mixed models with random effects. Pediatric GFR approaches the adult level by approximately 24 months of age [3], and the kidney grows slowly thereafter [22]. To study the changes associated with this critical time point, we implemented a piecewise linear mixed model to identify differences in the renal growth slope before and after the age of 24 months. The piecewise linear mixed-effects model allowed different linear functions of time corresponding to the periods before and after 24 months of age to obtain the renal growth slope in each time period $[23,24]$. The slope change at the time point of 24 months of age was also evaluated. We then investigated whether sex was associated with different renal growth slopes across groups. Statistical analyses were performed with SPSS version 25 (IBM Corp., Armonk, NY, USA) and SAS version 9.4 (SAS Institute Inc., Cary, NC, USA). A P-value $<0.05$ was considered to indicate statistical significance, except for multiple comparisons, where a cutoff of $\mathrm{P}<0.017$ was used.

\section{Results}

\section{Demographics and Clinical Results}

There were 1,375 renal ultrasonography examinations of 193 pediatric patients during the study period. Among these, 35 patients had unilateral renal agenesis, 62 patients had MCDK, and 96 patients had a history of nephrectomy for a primary renal tumor (95 for nephroblastoma and 1 for a rhabdoid tumor of the kidney). From the review of images, 61 patients with 896 examinations were excluded due to combined diffuse or focal lesions in the contralateral kidney. The percentages of excluded patients were $25.7 \%$ from the agenesis group, $43.5 \%$ from the MCDK group, and $26.0 \%$ from the nephrectomy group. Therefore, a total of 479 ultrasonography examinations of contralateral kidneys without gross lesions from 132 pediatric patients were analyzed in this study (Fig. 1).

There were 26 patients with 131 examinations in the agenesis group, 35 patients with 171 examinations in the MCDK group, and 71 patients with 177 examinations in the nephrectomy group. A summary of the demographics and laboratory findings of the three groups is presented in Table 1. There were 59 male and 73 female patients in total, and there were more female patients in the nephrectomy group compared to the other groups $(\mathrm{P}<0.05)$. The mean age at the time of all ultrasonographic evaluations was $36.4 \pm 39.4$ months, with a range of 0-204 months. The mean age at the time of the ultrasonography examinations was significantly older in the nephrectomy group (60.6 445.0 months) than in the other two groups (23.1 \pm 26.6 months in the agenesis group and $21.6 \pm 27.8$ months in the MCDK group, $P<0.001)$. The mean age at the time of initial ultrasonography was also older in the nephrectomy group than in the other two groups ( $P<0.001$ for both) (Table 1).

An analysis of laboratory findings indicated that only serum creatinine level was significantly different between the nephrectomy group and the MCDK group, and was higher in the nephrectomy group (mean, $0.43 \pm 0.17 \mathrm{mg} / \mathrm{dL}$ vs. $0.36 \pm 0.14 \mathrm{mg} / \mathrm{dL} ; \mathrm{P}<0.001$ ). The mean estimated GFR was $120.3 \pm 44.0 \mathrm{~mL} / \mathrm{min} / 1.73 \mathrm{~m}^{2}$ overall, with a range of $26.2-241.7 \mathrm{~mL} / \mathrm{min} / 1.73 \mathrm{~m}^{2}$. The estimated GFR was less than $90 \mathrm{~mL} / \mathrm{min} / 1.73 \mathrm{~m}^{2}$ in three patients in the agenesis group, seven in the MCDK group, and four in the nephrectomy group. Proteinuria was present in five patients in the agenesis group, six in the MCDK group, and 11 in the nephrectomy group.

\section{Renal Growth Results}

The mean number of follow-up visits for each patient was 5.0 in the agenesis group, 4.9 in the MCDK group, and 2.5 in the nephrectomy group. There were significantly fewer follow-up visits in the nephrectomy group than in the other two groups $(P<0.001)$ (Table 1).

The baseline size of the contralateral kidney was $5.3 \pm 1.4 \mathrm{~cm}$ in 


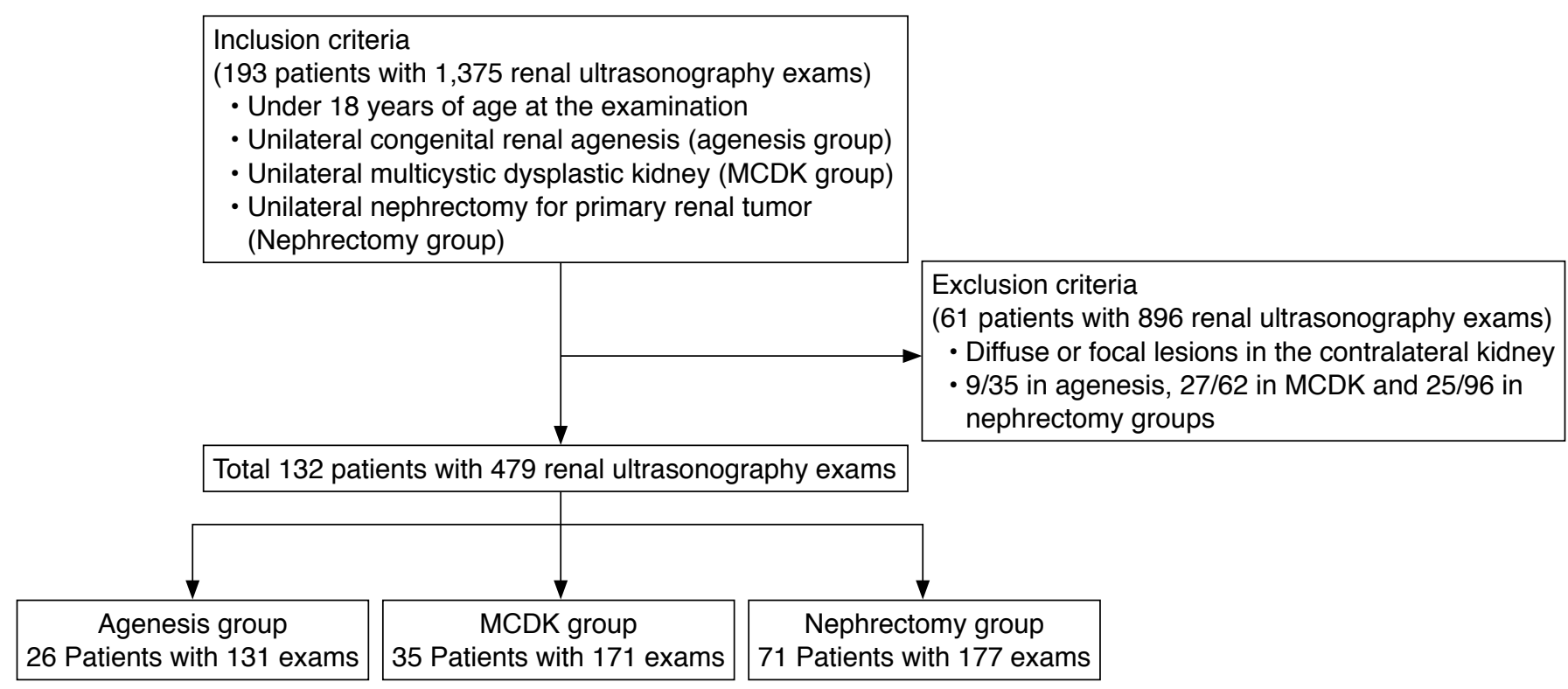

Fig. 1. Inclusion and exclusion criteria. MCDK, multicystic dysplastic kidney.

Table 1. Demographics, laboratory results, and renal ultrasonography examinations of patients in the agenesis, MCDK, and nephrectomy groups

\begin{tabular}{|c|c|c|c|c|c|c|c|c|}
\hline & \multirow{2}{*}{$\begin{array}{l}\text { Agenesis } \\
\text { group }\end{array}$} & \multirow{2}{*}{$\begin{array}{l}\text { MCDK } \\
\text { group }\end{array}$} & \multirow{2}{*}{$\begin{array}{l}\text { Nephrectomy } \\
\text { group }\end{array}$} & \multirow{2}{*}{$\begin{array}{l}\text { All three } \\
\text { groups }\end{array}$} & \multicolumn{4}{|c|}{ P-values for differences } \\
\hline & & & & & All groups & $\begin{array}{c}\text { Agenesis vs. } \\
\text { MCDK }\end{array}$ & $\begin{array}{l}\text { Agenesis vs. } \\
\text { nephrectomy }\end{array}$ & $\begin{array}{c}\text { MCDK vs. } \\
\text { nephrectomy }\end{array}$ \\
\hline No. of patients & 26 & 35 & 71 & 132 & & & & \\
\hline Sex (male: female) & $7: 19$ & $11: 24$ & $41: 30$ & $59: 73$ & 0.005 & 0.703 & 0.007 & 0.011 \\
\hline $\begin{array}{l}\text { Age at the time of initial } \\
\text { examination (month) }\end{array}$ & $\begin{array}{c}9.4 \pm 28.2 \\
(0-109)\end{array}$ & $\begin{array}{c}2.2 \pm 4.6 \\
(0-19)\end{array}$ & $\begin{array}{c}40.0 \pm 28.5 \\
(0-122)\end{array}$ & $\begin{array}{c}23.9 \pm 30.0 \\
(0-122)\end{array}$ & $<0.001$ & 0.212 & $<0.001$ & $<0.001$ \\
\hline $\begin{array}{l}\text { Age among all } \\
\text { examinations (month) }\end{array}$ & $\begin{array}{c}23.1 \pm 26.6 \\
(0-141)\end{array}$ & $\begin{array}{c}21.6 \pm 27.8 \\
(0-130)\end{array}$ & $\begin{array}{c}60.6 \pm 45.0 \\
(0-204)\end{array}$ & $\begin{array}{c}36.4 \pm 39.4 \\
(0-204)\end{array}$ & $<0.001$ & 0.636 & $<0.001$ & $<0.001$ \\
\hline \multicolumn{9}{|l|}{ Laboratory results } \\
\hline Serum creatinine (mg/dL) & $0.38 \pm 0.28$ & $0.36 \pm 0.14$ & $0.43 \pm 0.17$ & $0.39 \pm 0.20$ & 0.012 & 0.445 & 0.106 & $<0.001$ \\
\hline Cystatin C (mg/L) & $1.00 \pm 0.25$ & $1.06 \pm 0.31$ & $1.15 \pm 0.42$ & $1.06 \pm 0.32$ & 0.384 & 0.450 & 0.196 & 0.365 \\
\hline Proteinuria, n (\%) & $5(19.2)$ & $6(17.1)$ & $11(15.5)$ & $22(16.7)$ & 0.905 & 0.834 & 0.660 & 0.823 \\
\hline \multicolumn{9}{|l|}{ Renal ultrasonography } \\
\hline $\begin{array}{l}\text { Total number of } \\
\text { examinations }\end{array}$ & 131 & 171 & 177 & 479 & & & & \\
\hline $\begin{array}{l}\text { Examination number in } \\
\text { each patient }\end{array}$ & $\begin{array}{c}5.0 \pm 2.4 \\
(1-12)\end{array}$ & $\begin{array}{c}4.9 \pm 2.9 \\
(1-12)\end{array}$ & $\begin{array}{c}2.5 \pm 2.8 \\
(1-11)\end{array}$ & $\begin{array}{l}3.6 \pm 3.0 \\
(1-12)\end{array}$ & 0.020 & 0.827 & $<0.001$ & $<0.001$ \\
\hline $\begin{array}{l}\text { Baseline contralateral } \\
\text { kidney size }(\mathrm{cm})\end{array}$ & $\begin{array}{c}5.3 \pm 1.4 \\
(3.4-10.2)\end{array}$ & $\begin{array}{c}5.2 \pm 1.1 \\
(3.5-8.0)\end{array}$ & $\begin{array}{c}7.4 \pm 1.3 \\
(4.5-9.9)\end{array}$ & $\begin{array}{c}6.5 \pm 1.7 \\
(3.4-10.2)\end{array}$ & $<0.001$ & 0.874 & $<0.001$ & $<0.001$ \\
\hline $\begin{array}{l}\text { Overall contralateral kidney } \\
\text { size }(\mathrm{cm})\end{array}$ & $\begin{array}{c}6.8 \pm 1.7 \\
(3.4-11.0)\end{array}$ & $\begin{array}{c}7.0 \pm 1.7 \\
(3.5-12.0)\end{array}$ & $\begin{array}{c}8.3 \pm 1.7 \\
(4.5-13.7)\end{array}$ & $\begin{array}{c}7.4 \pm 1.8 \\
(3.4-13.7)\end{array}$ & $<0.001$ & 0.286 & $<0.001$ & $<0.001$ \\
\hline
\end{tabular}

Values are presented as mean \pm standard deviation (range) unless otherwise indicated.

MCDK, multicystic dysplastic kidney. 
the agenesis group, $5.2 \pm 1.1 \mathrm{~cm}$ in the MCDK group, and $7.4 \pm 1.3$ $\mathrm{cm}$ in the nephrectomy group. The baseline kidney size was larger in the nephrectomy group than in the other two groups $(P<0.001)$ (Table 1).

Fig. 2 demonstrates the renal growth trends in the three groups with normal reference lines from a previous study [22]. Supplementary Fig. 1 contains scatter plots showing the trends of renal growth in the three groups. While the baseline kidney size was the largest in the nephrectomy group, the increment of renal growth was smaller in that group than in the other two groups $(P=0.004$ compared with the agenesis group and $\mathrm{P}<0.001$ compared with the MCDK group) (Table 2). When separately considering the renal growth slope before and after 24 months of age, we found that kidney size increased significantly in all three groups before 24 months of age, with a growth slope of $0.101-0.104 \mathrm{~cm} / \mathrm{mo}$, while growth slowed to $0.025-0.032 \mathrm{~cm} / \mathrm{mo}$ after 24 months of age $(P<0.001)$. As shown in Table 2 , the growth slope was not different among the groups before $(P=0.839-0.929)$ or after $(P=0.262-$ 0.697) 24 months of age. Renal growth in boys and girls were not significantly different (Supplementary Table 1).

\section{Discussion}

For pediatric patients, kidney injury or disease can impact quality of life, and some patients live with only a solitary functioning kidney due to congenital or acquired reasons. This study included cases of unilateral renal agenesis, MCDK, and unilateral nephrectomy for primary renal tumors, as patients with these conditions are known to exhibit compensatory renal growth. The renal growth slope was similar among the three groups, with a growth slope of about 0.1 $\mathrm{cm} /$ month before 24 months of age and about $0.03 \mathrm{~cm} / \mathrm{mo}$ after 24 months of age. The growth slope was similar to that of normal kidneys before 24 months of age $(0.1 \mathrm{~cm} / \mathrm{mo})$ but faster than that of normal kidneys after 24 months of age $(0.02 \mathrm{~cm} / \mathrm{mo})$ [25]. These growth slopes can be useful in follow-up kidney size assessments throughout childhood.

In this study, the nephrectomy group was older, with larger kidneys, higher serum creatinine levels, and a lower overall renal growth slope. Because kidney size, renal growth slope, and serum creatinine levels are associated with age in children [20,22], we cannot conclude that this finding reflects a pathologic difference between the groups. Pediatric GFR increases to the adult level by
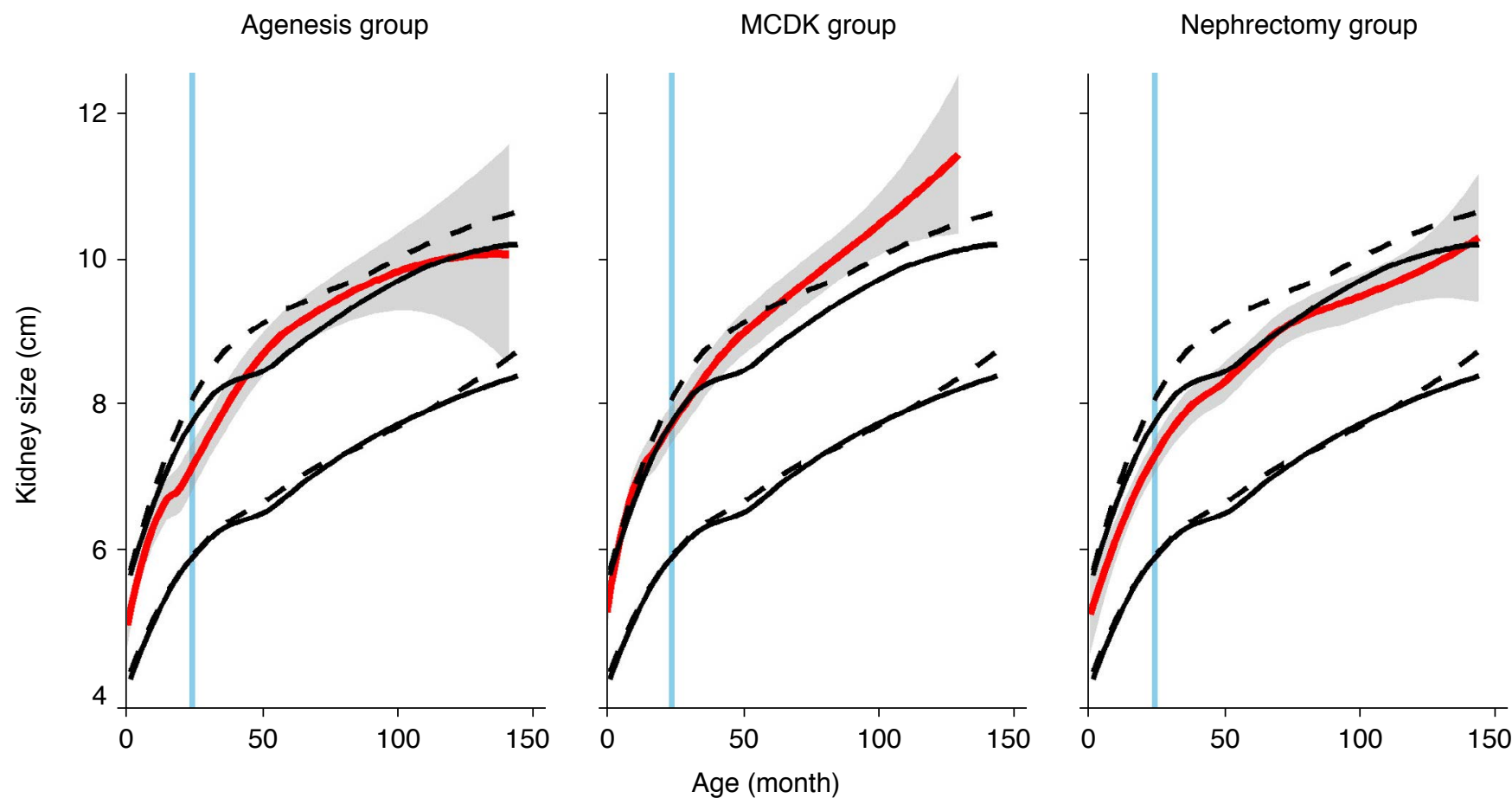

Fig. 2. Growth slope of contralateral kidneys according to age among the three groups: agenesis, multicystic dysplastic kidney (MCDK), and nephrectomy. Spaghetti plots demonstrate the growth slope of the contralateral kidneys; the gray zone indicates the range of the contralateral kidneys in our study, and the red line indicates the estimated mean value at each age time point. The blue line indicates the age of 24 months. The solid lines are the normal range of right kidneys and the dotted lines are the normal range of left kidneys, following a previous study [22]. There was a significant difference in the renal growth slope before and after 24 months of age, from $0.101-0.104 \mathrm{~cm} /$ mo to $0.025-0.032 \mathrm{~cm} / \mathrm{mo}$, and the results were similar for all three groups $(\mathrm{P}<0.001)$. 
Table 2. Contralateral kidney growth slope in patients in the agenesis, MCDK, and nephrectomy groups

\begin{tabular}{|c|c|c|c|c|c|c|c|c|c|}
\hline & \multicolumn{2}{|c|}{ Agenesis group } & \multicolumn{2}{|c|}{ MCDK group } & \multicolumn{2}{|c|}{ Nephrectomy group } & \multicolumn{3}{|c|}{ P-values for differences } \\
\hline & Estimate & Standard error & Estimate & Standard error & Estimate & Standard error & $\begin{array}{l}\text { Agenesis } \\
\text { vs. MCDK }\end{array}$ & $\begin{array}{l}\text { Agenesis vs. } \\
\text { nephrectomy }\end{array}$ & $\begin{array}{c}\text { MCDK vs. } \\
\text { nephrectomy }\end{array}$ \\
\hline \multicolumn{10}{|l|}{ Overalla) } \\
\hline Overall slope & 0.062 & 0.006 & 0.070 & 0.006 & 0.041 & 0.004 & 0.365 & 0.004 & $<0.001$ \\
\hline \multicolumn{10}{|l|}{ Considering 24 mo of age ${ }^{b)}$} \\
\hline Slope before $24 \mathrm{mo}$ of age & 0.104 & 0.010 & 0.103 & 0.009 & 0.101 & 0.012 & 0.929 & 0.839 & 0.893 \\
\hline Slope after 24 mo of age & 0.029 & 0.005 & 0.032 & 0.005 & 0.025 & 0.003 & 0.697 & 0.528 & 0.262 \\
\hline Slope change at 24 mo & -0.075 & 0.013 & -0.071 & 0.011 & -0.076 & 0.014 & 0.810 & 0.976 & 0.792 \\
\hline
\end{tabular}

MCDK, multicystic dysplastic kidney.

a) From the linear mixed model. ${ }^{b}$ From a piecewise linear mixed model using 24 months of age as the break time point.

2 years of age [3], and kidneys show rapid growth during the first 24 months of life and slow down afterwards [22]. In addition, the nephrectomy group had fewer ultrasonographic examinations, which may have been due to differences in the workup pattern of imaging studies in the nephrectomy group, which also included computed tomography and magnetic resonance imaging to evaluate tumor progression, whereas patients with congenital solitary functioning kidneys only underwent ultrasonography during follow-up.

One of the key differences between congenital and acquired solitary functioning kidneys is the degree of nephron deficiency, which is generally more severe in acquired disease because it usually occurs after completion of nephrogenesis. Nephrogenesis is complete at approximately 34 to 36 weeks of gestation, after which no new nephrons form. Therefore, in acquired solitary functioning kidneys, fewer nephrons are available to compensate for hyperfiltration and hypertrophy than is the case in congenital conditions [26].

Unilateral renal agenesis causes intra-uterine compensatory renal growth, which can affect postnatal renal function [27]. MCDK can also cause compensatory hypertrophy of solitary functioning kidneys in utero [28]. In the postnatal period, $65 \%-97 \%$ of solitary functioning kidneys show compensatory renal hypertrophy by $18-$ 30 months of age [28-30]. However, the rate of compensatory hypertrophy can vary from $24 \%$ to $81 \%$ [31].

The reported rate of compensatory contralateral renal hypertrophy after nephrectomy in patients with nephroblastoma is $68 \%-93 \%$ [32-34]. One study published in 1996 demonstrated that the frequency of contralateral renal hypertrophy was not related to age at nephrectomy, side of the solitary functioning kidney, tumor stage, chemotherapy regimen, or treatment with radiation therapy [17]. However, another study showed that kidney size was inversely correlated with age at nephrectomy [35].

Only a few studies have compared contralateral renal hypertrophy in unilateral renal agenesis and nephrectomy due to nephroblastoma. One study performed in 1976 showed that, in unilateral renal agenesis, the contralateral kidney was initially smaller than the bilateral normal mean, but increased with a steeper slope than the standard, resulting in a larger size than normal [19]. In comparison, in patients who underwent nephrectomy due to nephroblastoma, the preoperative contralateral normal kidney was larger than average and showed further compensatory growth after surgery. In addition, the overall growth slope tended to be steeper in patients who underwent nephrectomy due to nephroblastoma than in those with unilateral renal agenesis [19]. However, those findings are from an old study in which the mean patient age at diagnosis was 4 years and urography was used to measure kidney size. In 1988, another study showed no renal hypertrophy at the time of birth in patients with unilateral renal agenesis, whereas by at least 4 years of age, these patients showed hypertrophy accounting for roughly $190 \%$ of the volume of the healthy kidney [36]. The nephrectomy group showed similar levels of renal hypertrophy, up to $180 \%$ of the volume of the healthy kidney, within 2-4 years after nephrectomy. However, those studies did not evaluate the renal growth slope between the two groups.

In this study, the renal growth slope between congenital and acquired solitary functioning kidneys were similar when using the age of 24 months as a transition point. Fig. 2 and Supplementary Fig. 1 also show similar patterns of growth in the three groups, even though the overall slope of renal growth was smaller in the nephrectomy group. This may have been due to the effect of the older age of the nephrectomy group than the congenital groups. To date, only one study has documented the renal growth rate of the contralateral kidney in patients with MCDK [37]. Contralateral hypertrophy was seen at birth and maintained during childhood, with a growth rate of $0.89 \mathrm{~cm} / \mathrm{y}(0.07 \mathrm{~cm} / \mathrm{mo})$ overall and $0.61 \mathrm{~cm} /$ y $(0.05 \mathrm{~cm} / \mathrm{mo})$ in two nephrectomy cases associated with MCDK; these rates are similar to our results. Although our research did not involve pathological tests, these growth slopes require further 
verification of the existing hypotheses of nephrogenesis and renal growth in congenital and acquired solitary functioning kidneys.

Additionally, glomerular hyperfiltration can lead to renal injury, which can result in hypertension, microalbuminuria, and chronic kidney disease [38]. Decreased size of the functioning kidney is also associated with a risk of renal injury [5]. For this reason, follow-up assessment of contralateral renal growth is important, especially in children. Animal studies demonstrated an increased number of nephrons in congenital solitary functioning kidneys $[39,40]$. This indicates that patients with a congenital solitary functioning kidney might not be at an increased risk for hyperfiltration-associated renal and cardiovascular disease due to a lower nephron number. However, in our study, 15\%-20\% of the patients in each group and $16.7 \%$ overall experienced proteinuria during follow-up, and the estimated GFR was not different between the groups. Furthermore, it was difficult to classify abnormalities by assessing the normal ranges of blood pressure and GFR according to the age of the patients. Further research into the pathophysiological status of congenital and acquired solitary functioning kidneys and the corresponding clinical impact is needed.

There were several limitations to this study. First, the follow-up examinations in this study spanned more than 16 years. Depending on the timing of the examinations, there were variations in the ultrasonographic equipment used. In addition, several different examiners conducted the renal scanning, which can result in interoperator variation, even though one radiologist re-evaluated the kidney size to reduce inter-observer variability. However, follow-up renal growth assessment in pediatric patients is a long-term task, so long-term data may be more valuable and representative of reality. Second, the relationship between kidney size and renal function has not been clarified. The study identified only gross kidney size and did not pathologically identify any changes in glomeruli or interstitial tissue. Even though we excluded patients with gross renal lesions such as renal echo changes or cysts, it was not possible to guarantee that all kidneys in the patients were fully normal. Therefore, future research will require modalities to distinguish earlier between normal kidneys and kidneys with impaired function in pediatric patients with congenital or acquired solitary functioning kidneys.

In conclusion, we analyzed the renal growth slope in pediatric patients with congenital (agenesis and MCDK) and acquired (nephrectomy for renal tumors) solitary functioning kidneys. The baseline contralateral kidney size and overall growth slope were different. However, using 24 months of age as the assumed time point for reaching adult renal function, the renal growth slope was similar among the three groups; specifically, growth was faster before 24 months of age (about $0.1 \mathrm{~cm} / \mathrm{mo}$ ) and slower thereafter (about $0.03 \mathrm{~cm} / \mathrm{mo}$ ). These findings on the slope of renal growth can help guide follow-up and monitoring approaches for pediatric patients with congenital or acquired solitary functioning kidneys.

ORCID: Seung Myeon Choi: https://orcid.org/0000-0003-1971-388X; Hyun Joo Shin: https://orcid.org/0000-0002-7462-2609; Haesung Yoon: https://orcid.org/00000003-0581-8656; Myeongjee Lee: https://orcid.org/0000-0003-2368-5180; Yong Seung Lee: https://orcid.org/0000-0003-3778-9888; Sang Won Han: https:// orcid.org/0000-0003-0941-1300; Mi-Jung Lee: https://orcid.org/0000-0003-32449171

\section{Author Contributions}

Conceptualization: Lee MJ. Data acquisition: Choi SM, Shin HJ, Yoon H, Lee YS, Han SW, Lee MJ. Data analysis or interpretation: Choi SM, Lee M, Lee MJ. Drafting of the manuscript: Choi SM, Shin HJ, Yoon $\mathrm{H}$, Lee M, Lee MJ. Critical revision of the manuscript: Choi SM, Lee MJ. Approval of the final version of the manuscript: all authors.

\section{Conflict of Interest}

No potential conflict of interest relevant to this article was reported.

\section{Supplementary Material}

Supplementary Table 1. Contralateral grossly normal kidney growth patterns in patients in the agenesis, MCDK, and nephrectomy groups with adjustment for sex (https://doi.org/10.14366/usg.20028).

Supplementary Fig. 1. Scatter plots of contralateral kidney size according to age in the three groups: agenesis, multicystic dysplastic kidney (MCDK), and nephrectomy. Scatter plots show similar trends of renal growth slope in the three groups (https://doi.org/10.14366/ usg.20028).

\section{References}

1. Bertram JF, Douglas-Denton RN, Diouf B, Hughson MD, Hoy WE. Human nephron number: implications for health and disease. Pediatr Nephrol 2011;26:1529-1533.

2. Kim JH, Kim MJ, Lim SH, Kim J, Lee MJ. Length and volume of morphologically normal kidneys in korean children: ultrasound measurement and estimation using body size. Korean J Radiol 2013;14:677-682.

3. Heilbron DC, Holliday MA, al-Dahwi A, Kogan BA. Expressing glomerular filtration rate in children. Pediatr Nephrol 1991;5:5-11.

4. Westland R, Schreuder MF, van Goudoever JB, Sanna-Cherchi S, van Wijk JA. Clinical implications of the solitary functioning kidney. Clin J Am Soc Nephrol 2014;9:978-986.

5. Westland R, Kurvers RA, van Wijk JA, Schreuder MF. Risk factors for renal injury in children with a solitary functioning kidney. Pediatrics 2013;131:e478-e485. 
6. Westland R, Schreuder MF, Ket JC, van Wijk JA. Unilateral renal agenesis: a systematic review on associated anomalies and renal injury. Nephrol Dial Transplant 2013;28:1844-1855.

7. Dursun $H$, Bayazit AK, Buyukcelik M, Soran M, Noyan A, Anarat A. Associated anomalies in children with congenital solitary functioning kidney. Pediatr Surg Int 2005;21:456-459.

8. Sanna-Cherchi S, Ravani P, Corbani V, Parodi S, Haupt R, Piaggio G, et al. Renal outcome in patients with congenital anomalies of the kidney and urinary tract. Kidney Int 2009;76:528-533.

9. Schreuder MF, Westland R, van Wijk JA. Unilateral multicystic dysplastic kidney: a meta-analysis of observational studies on the incidence, associated urinary tract malformations and the contralateral kidney. Nephrol Dial Transplant 2009;24:1810-1818.

10. La Scola C, Ammenti A, Puccio G, Lega MV, De Mutiis C, Guiducci $C$, et al. Congenital solitary kidney in children: size matters. J Urol 2016;196:1250-1256.

11. Metcalfe PD, Wright JR Jr, Anderson PA. MCDK not excluded by virtue of function on renal scan. Can J Urol 2002;9:1690-1693.

12. Zambaiti E, Sergio M, Baldanza F, Corrado C, Di Pace MR, Cimador M. Correlation between hypertrophy and risk of hypertension in congenital solitary functioning kidney. Pediatr Surg Int 2019;35:167-174.

13. Pastore G, Znaor A, Spreafico F, Graf N, Pritchard-Jones K, Steliarova-Foucher $\mathrm{E}$. Malignant renal tumours incidence and survival in European children (1978-1997): report from the Automated Childhood Cancer Information System project. Eur J Cancer 2006;42:2103-2114.

14. Green DM. The evolution of treatment for Wilms tumor. J Pediatr Surg 2013;48:14-19.

15. Drozdzik M, Domanski L, Rozanski J, Gorecka B. Functional evaluation of the remaining kidney in patients after unilateral nephrectomy. Scand J Urol Nephrol 2003;37:159-163.

16. Schreuder MF. Life with one kidney. Pediatr Nephrol 2018;33:595604.

17. Zerin JM, Haliloglu M, Cohen MD. Growth of the solitary kidney after nephrectomy in children with unilateral Wilms' tumor. Pediatr Radiol 1996;26:547-552.

18. Abidari JM, Park KH, Kennedy WA, Shortliffe LD. Serial followup of the contralateral renal size in children with multicystic dysplastic kidney. J Urol 2002;168:1821-1825.

19. Eklof $\mathrm{O}$, Ringertz H. Kidney size and growth in unilateral renal agenesis and in the remaining kidney following nephrectomy for Wilms' tumor. Acta Radiol Diagn (Stockh) 1976;17:601-608.

20. van Donge T, Welzel T, Atkinson A, van den Anker J, Pfister M. Agedependent changes of kidney injury biomarkers in pediatrics. J Clin Pharmacol 2019;59 Suppl 1:S21-S32.

21. Carrico CW, Zerin JM. Sonographic measurement of renal length in children: does the position of the patient matter? Pediatr Radiol 1996;26:553-555.
22. Oh MS, Hwang G, Han S, Kang HS, Kim SH, Kim YD, et al. Sonographic growth charts for kidney length in normal Korean children: a prospective observational study. J Korean Med Sci 2016;31:1089-1093.

23. Bozdogan H. Model selection and Akaike's Information Criterion (AIC): the general theory and its analytical extensions. Psychometrika 1987;52:345-370.

24. Fitzmaurice GM, Laird NM, Ware JH. Applied longitudinal analysis. Hoboken, NJ: Wiley, 2012.

25. Kim IO, Cheon JE, Lee YS, Lee SW, Kim OH, Kim JH, et al. Kidney length in normal Korean children. J Korean Soc Ultrasound Med 2010;29:181-188.

26. Spira EM, Jacobi C, Frankenschmidt A, Pohl M, von Schnakenburg C. Sonographic long-term study: paediatric growth charts for single kidneys. Arch Dis Child 2009;94:693-698.

27. Perlman $S$, Lotan D, Dekel B, Kivilevitch $Z$, Hazan $Y$, Achiron R, et al. Prenatal compensatory renal growth in unilateral renal agenesis. Prenat Diagn 2016;36:1075-1080.

28. Rottenberg GT, De Bruyn R, Gordon I. Sonographic standards for a single functioning kidney in children. AJR Am J Roentgenol 1996;167:1255-1259.

29. Alaygut D, Soylu A, Kasap B, Turkmen M, Cakmakci H, Kavukcu $S$. The relationships between renal compensatory hypertrophy etiologic factors and anthropometric development in the pediatric age group. Urology 2013;82:442-447.

30. Rabelo EA, Oliveira EA, Diniz JS, Silva JM, Filgueiras MT, Pezzuti IL, et al. Natural history of multicystic kidney conservatively managed: a prospective study. Pediatr Nephrol 2004;19:1102-1107.

31. Hains DS, Bates CM, Ingraham S, Schwaderer AL. Management and etiology of the unilateral multicystic dysplastic kidney: a review. Pediatr Nephrol 2009;24:233-241.

32. Kosiak M, Stefanowicz J, Adamkiewicz-Drozynska E, Balcerska A, Kurylak A, Demidowicz E. Sonographic image of solitary kidney in Wilms tumour survivors. Kidney Blood Press Res 2018;43:13631374.

33. Neu MA, Russo A, Wingerter A, Alt F, Theruvath J, El Malki K, et al. Prospective analysis of long-term renal function in survivors of childhood Wilms tumor. Pediatr Nephrol 2017;32:1915-1925.

34. Kostel Bal AS, Yalcin B, Susam-Sen H, Aydin B, Varan A, Kutluk T, et al. Renal late effects after the treatment of unilateral nonsyndromic Wilms tumor. J Pediatr Hematol Oncol 2016;38:e147-e150.

35. Di Tullio MT, Casale F, Indolfi P, Polito C, Giuliano M, Martini A, et al. Compensatory hypertrophy and progressive renal damage in children nephrectomized for Wilms' Tumor. Med Pediatr Oncol 1996;26:325-328.

36. Dinkel E, Britscho J, Dittrich M, Schulte-Wissermann H, Ertel M. Renal growth in patients nephrectomized for Wilms tumour as compared to renal agenesis. Eur J Pediatr 1988;147:54-58.

37. White R, Greenfield SP, Wan J, Feld L. Renal growth characteristics 
in children born with multicystic dysplastic kidneys. Urology 1998;52:874-877.

38. Helal I, Fick-Brosnahan GM, Reed-Gitomer B, Schrier RW. Glomerular hyperfiltration: definitions, mechanisms and clinical implications. Nat Rev Nephrol 2012;8:293-300.

39. Douglas-Denton R, Moritz KM, Bertram JF, Wintour EM.
Compensatory renal growth after unilateral nephrectomy in the ovine fetus. J Am Soc Nephrol 2002;13:406-410.

40. van Vuuren SH, Sol CM, Broekhuizen R, Lilien MR, Oosterveld MJ, Nguyen TQ, et al. Compensatory growth of congenital solitary kidneys in pigs reflects increased nephron numbers rather than hypertrophy. PLoS One 2012;7:e49735. 